\title{
Are Sham Acupuncture Interventions More Effective than (Other) Placebos? A Re-Analysis of Data from the Cochrane Review on Placebo Effects
}

\author{
Klaus Linde ${ }^{a}$ Karin Niemann ${ }^{a} \quad$ Karin Meissner ${ }^{a, b}$ \\ ${ }^{a}$ Institute of General Practice, Technische Universität München, \\ ${ }^{\mathrm{b}}$ Institute of Medical Psychology, Ludwig-Maximilians University, Munich, Germany
}

\section{Keywords}

Acupuncture · Placebo effects - Sham acupuncture .

Randomized controlled trial · Meta-analysis

\section{Summary}

Background and Objective: A recent Cochrane review on placebo interventions for all kinds of conditions found that 'physical placebos' (which included sham acupuncture) were associated with larger effects over no-treatment control groups than 'pharmacological placebos'. We re-analyzed the data from this review to investigate whether effects associated with sham acupuncture differed from those of other 'physical placebos'. Methods: All trials included in the Cochrane review as investigating 'physical placebos' were classified as investigating either (sham) acupuncture or other physical placebos. The latter group was further subclassified into groups of similar interventions. Data from the Cochrane review were re-entered into the RevMan 5 software for meta-analysis. The primary analysis was a random-effects analysis of trials reporting continuous outcomes of trials that used either sham acupuncture or other physical placebos. Results: Out of a total of 61 trials which reported a continuous outcome measure, 19 compared sham acupuncture and 42 compared other physical placebos with a notreatment control group. The trials re-analyzed were highly heterogeneous regarding patients, interventions and outcomes measured. The pooled standardized mean difference was -0.41 (95\% confidence interval $-0.56,-0.24)$ between sham acupuncture and no treatment and $-0.26(95 \% \mathrm{Cl}-0.37,-0.15)$ between other physical placebos and no treatment ( $p$ value for subgroup differences $=0.007$ ). Significant differences were also observed between subgroups of other physical placebos. Conclusion: Due to the heterogeneity of the trials included and the indirect comparison our results must be interpreted with caution. Still, they suggest that sham acupuncture interventions might, on average, be associated with larger effects than pharmacological and other physical placebos.

\author{
Schlüsselwörter \\ Akupunktur · Placeboeffekte · Scheinakupunktur . \\ Randomisierte klinische Studie · Meta-Analyse
}

\section{Zusammenfassung}

Hintergrund und Fragestellung: In einem aktuellen CochraneReview zu Placeboeffekten in klinischen Studien ergab sich, dass "physikalische Placebos" (inklusive Scheinakupunktur) mit größeren Effekten gegenüber unbehandelten Kontrollgruppen assoziiert waren als "pharmakologische Placebos". Die Daten dieses Reviews wurden reanalysiert, um zu untersuchen, ob sich die mit Scheinakupunktur assoziierten Effekte von denen anderer "physikalischer Placebos" unterscheiden. Methoden: Alle in den Cochrane-Review eingeschlossenen Studien mit "physikalischen Placebos" wurden in Studien mit Scheinakupunktur und Studien mit anderen physikalischen Placebos unterteilt. Die zweite Gruppe wurde weiter unterteilt in Gruppen ähnlicher Interventionen. Die Daten des CochraneReviews wurden in die RevMan-5-Software eingegeben und ausgewertet. Als Hauptauswertung wurde eine RandomEffects-Analyse der Studien mit Scheinakupunktur und anderen physikalischen Placebos mit kontinuierlichen Zielgrößen durchgeführt. Ergebnisse: Von insgesamt 61 Studien mit einer kontinuierlichen Zielgröße verglichen 19 eine Scheinakupunkturintervention und 42 ein andere physikalische Placebointervention mit Nichtbehandlung. Die Studien waren in hohem Maße heterogen bezüglich Patienten, Interventionen und Zielkriterien. Die gepoolte standardisierte Mittelwertsdifferenz betrug $-0,41$ (95\%-Konfidenzintervall: $-0,56 ;-0,24)$ für den Vergleich Scheinakupunktur versus Nichtbehandlung und $-0,26$ $(-0,37 ;-0,15)$ für den Vergleich andere physikalische Placebos versus Nichtbehandlung ( $p$-Wert für Unterschiede zwischen den Subgruppen $=0,007$ ). Signifikante Unterschiede traten auch zwischen den weiteren Subgruppen physikalischer Placebos auf. Schlussfolgerung: Aufgrund des indirekten Vergleichs und der ausgeprägten klinischen Heterogenität der Studien müssen die Ergebnisse mit Zurückhaltung interpretiert werden. Sie deuten aber darauf hin, dass Scheinakupunkturinterventionen im Durchschnitt mit größeren Effekten einhergehen als pharmakologische und andere physikalische Placebos.

\begin{tabular}{ll}
\hline KARGER & ( ) 2010 S. Karger GmbH, Freiburg \\
Fax +497614520714 & $\begin{array}{l}\text { Accessible online at: } \\
\text { www.karger.com/fok }\end{array}$ \\
$\begin{array}{l}\text { Information@Karger.de } \\
\text { www.karger.com }\end{array}$ &
\end{tabular}




\section{Introduction}

Placebo-controlled trials are a crucial tool to investigate whether the clinical effects of an intervention are truly due to the 'specific' or 'characteristic' elements of an intervention [1, 2]. In the case of complex interventions it is often not easy to define which aspects are 'specific' or 'characteristic' and which are 'non-specific' or 'incidental'. As a consequence, it is difficult to devise an adequate placebo or sham intervention which is both inert and indistinguishable from the true intervention. Furthermore, even if inert on a physiological level, some placebos might be more powerful than others on a symbolical level. It has been argued both that sham acupuncture interventions might be particularly potent placebos [3] and that most sham acupuncture interventions are physiologically active [4]. If sham acupuncture (and other complex sham interventions) - for any of the two reasons mentioned or a combination of both reasons - would indeed be associated with larger improvements than, for example, a pharmacological placebo this could make it more difficult to show 'specific' effects for acupuncture and other complex interventions than for drugs.

The most straightforward way to investigate whether sham acupuncture is associated with larger effects than, for example, a medical placebo would be in randomized trials including both these interventions. Such trials are extremely rare, but the few available findings indeed suggest that sham acupuncture and other complex interventions are associated with larger effects than medical placebos [3,5]. Another, albeit methodologically weaker, possibility is to compare differences between sham acupuncture interventions and no-treatment control groups in acupuncture trials with those of (other) placebos and no-treatment control groups in other trials. Hrobjartsson and Gøtzsche have repeatedly reviewed all available trials including both a placebo or sham and a no-treatment group for any condition [6-8]. The latest update of their Cochrane review includes a total of 234 trials. In a pre-planned subgroup analysis they found that studies using 'physical placebos' (including sham acupuncture) reported larger 'placebo effects' (standardized mean difference (SMD) -0.31; 95\% confidence interval (CI) $-0.41,-0.22)$ than studies using 'pharmacological placebos' (SMD -0.10; 95\% CI -0.20, -0.01) [8]. If acupuncture was indeed a symbolically powerful intervention and/or if sham acupuncture interventions were not physiologically inert, sham acupuncture interventions could have larger effects over no-treatment controls than other 'physical placebos.' We re-analyzed the data by Hrobjartsson and Gøtzsche to investigate this hypothesis.

\section{Methods}

Methods and findings of the review by Hrobjartsson and Gøtzsche are described in detail in the original publication [8]. Their review included randomized trials on any condition which had both a placebo or sham group and a no-treatment group (or more exactly, a group which did not receive any intervention that was not also received in the sham group). In their main analysis Hrobjartsson and Gøtzsche pooled all trials with continuous or dichotomous outcomes regardless of conditions, interventions and outcomes assessed. In addition, they performed a large number of subgroup analyses to investigate whether these factors as well as design features had an impact on outcomes. Our re-analyses are based on their comparison 7.6 which included 61 trials using 'physical placebos' (other categories were psychological and pharmacological placebos) and reporting data for a continuous outcome measure. Furthermore, we also re-analyzed comparison 7.2 which included 11 additional trials reporting dichotomous outcomes. One of us went through the table of studies included in the review and classified the interventions provided in the trials into acupuncture studies and other studies. The latter were then categorized further into clinically more homogeneous subgroups of at least 4 trials each. Another reviewer then re-entered the outcome data extracted and reported by Hrobjartsson and Gøtzsche into the Cochrane Collaboration's Review Manager Software 5 (RevMan 5). The third reviewer checked all data entries against those in the original review. Like Hrobjartsson and Gøtzsche we calculated SMDs (difference between the means of the groups compared, divided by the pooled standard deviation) for trials reporting continuous outcome measures (with negative values indicating superiority of sham over no treatment) and risk ratios for dichotomous outcomes (with values $<1$ indicating superiority of sham over no treatment). We then performed random-effects meta-analyses using the inverse variance method. To investigate statistical heterogeneity, RevMan 5 uses $\mathrm{Tau}^{2}, \mathrm{Chi}^{2}$ and $\mathrm{I}^{2}$. We considered $\mathrm{I}^{2}$ values between $30 \%$ and $60 \%$ as indicating moderate heterogeneity and higher values as indicating substantial heterogeneity. Subgroup comparisons were performed using the method implemented in RevMan 5 [9]. It has to be taken into account that $\mathrm{p}$ values for subgroup differences can be calculated only for fixed-effects estimates by this software. The primary analysis was acupuncture trials versus all other trials with continuous outcomes. In addition, we performed an analysis for dichotomous outcome measures as well as subgroup and sensitivity analyses to test the robustness of the results.

\section{Results}

The Cochrane review included a total of 19 (sham) acupuncture trials which reported continuous outcomes [10-28] and 5 acupuncture trials which reported a dichotomous outcome [29-33]. These 24 acupuncture studies addressed a great variety of conditions and interventions (table 1). One of the studies used as sham treatment an intervention we consider as true acupuncture: in the sham group patients with postoperative pain received acupuncture at point ST 36, whereas in the patients of the experimental group the needles were additionally also stimulated electrically [20]. As an exclusion of that study did not have a major impact on the pooled effect estimate (table 2) we included it in our analyses to keep the data set as similar as possible to the original one by Hrobjartsson and Gøtzsche.

Out of the 42 studies using 'physical placebos' 11 trials investigated either acupressure or laser acupuncture, 10 trials were on transcutaneous electrical nerve stimulation, 7 trials investigated electrotherapy, ultrasound or a physiotherapeutic intervention, 4 trials were on osteopathy or chiropractic 
Table 1. Acupuncture studies included in the Cochrane review [8]
Table 2. Additional analyses

\begin{tabular}{|c|c|c|c|}
\hline First author, year [ref] & $\mathrm{N}^{*}$ & Condition & Sham (number of sessions) \\
\hline \multicolumn{4}{|c|}{ Trials with continuous outcome } \\
\hline Allen, 1998 [11] & 22 & depression & needling at non-indicated points (12) \\
\hline Allen, $2006[10]$ & 89 & depression & needling at non-indicated points (12) \\
\hline Brinkhaus, 2006 [12] & 144 & chronic low back pain & needling outside of points (12) \\
\hline Cabrini, 2006 [13] & 32 & bronchoscopy & needling outside of points (1) \\
\hline Foster, 2007 [14] & 217 & osteaoarthritis of the knee & placebo needles at correct points (6) \\
\hline Helms, 1987 [15] & 22 & primary dysmenorrhea & needling outside of points (9) \\
\hline Kaptchuk, 2008 [16] & 175 & irritable bowel syndrome & placebo needles outside of points (6) \\
\hline Karst, 2007 [17] & 29 & tooth extraction & placebo needles outside of points (1) \\
\hline Kotani, 2001 [18] & 47 & pain at abdominal scares & needling outside of points (20) \\
\hline Leibing, $2002[19]$ & 79 & chronic low back pain & needling outside of points (20) \\
\hline Lin, $2002[20]$ & 50 & postoperative pain & needling of ST 36 without electro-stimulation (1) \\
\hline Linde, $2005[21]$ & 157 & migraine & needling outside of points (12) \\
\hline Medici, 2002 [22] & 41 & asthma & needling outside of points (16) \\
\hline Melchart, 2005 [23] & 120 & tension-type headache & needling outside of points (12) \\
\hline Röschke, 2000 [24] & 48 & depression & needling outside of points (12) \\
\hline Rösler, 2003 [25] & 27 & transesoph. echocardiogr. & needling outside of points (1) \\
\hline Shen, $2000[26]$ & 67 & chemotherapy-ind. nausea & needling outside of points (5) \\
\hline Tremeau, 1992 [27] & 64 & cervical maturation & needling outside of points ( 3 ) \\
\hline Witt, 2005 [28] & 140 & osteoarthritis of the knee & needling outside of points (12) \\
\hline \multicolumn{4}{|c|}{ Trials with dichotomous outcomes } \\
\hline Aune, 2002 [29] & 40 & recurrent urinary tract inf. & needling outside of points (1) \\
\hline Dundee, $1986[30]$ & 50 & postoperative nausea & needling outside of points (8) \\
\hline Fanti, 2003 [31] & 20 & coloscopy & needling outside of points (1) \\
\hline Molsberger, 2002 [32] & 111 & chronic low back pain & needling outside of points (12) \\
\hline Scharf, $2006[33]$ & 681 & osteoarthritis of the knee & needling outside of points (10 to 15 ) \\
\hline
\end{tabular}

\begin{tabular}{|c|c|c|}
\hline Analysis & SMD $(95 \%$ CI) random effects & $\mathrm{I}^{2} / \mathrm{p}$ value \\
\hline \multicolumn{3}{|l|}{ Trials with continous outcome measures } \\
\hline Acupuncture trials without Lin, $2002(\mathrm{n}=18)$ & $-0.40(-0.56,-0.25)$ & $51 \%$ \\
\hline Acupuncture trials without ART trials $(\mathrm{n}=15)$ & $-0.30(-0.46,-0.13)$ & $33 \%$ \\
\hline \multicolumn{3}{|l|}{ Intervention subgroup analysis } \\
\hline - Acupressure and laser acupuncture trials $(\mathrm{n}=11)$ & $-0.20(-0.35,-0.04)$ & $0 \%$ \\
\hline - Transcutaneous nerve stimulation trials $(\mathrm{n}=10)$ & $-0.11(-0.24,0.02)$ & $0 \%$ \\
\hline - Physio-, electro- and ultrasound therapy trials $(\mathrm{n}=7)$ & $-0.52(-0.74,-0.30)$ & $0 \%$ \\
\hline - Chiropractic and osteopathy trials $(n=4)$ & $-0.40(-0.88,0.08)$ & $0 \%$ \\
\hline - Other trials $(\mathrm{n}=10)$ & $-0.26(-0.66,0.14)$ & $72 \%$ \\
\hline Test for subgroup differences & & 0.01 \\
\hline \multicolumn{3}{|l|}{ Sham type analysis } \\
\hline - Sham interventions with skin penetration $(\mathrm{n}=16)$ & $-0.43(-0.59, .0 .28)$ & $39 \%$ \\
\hline - Sham interventions without skin penetration $(\mathrm{n}=3)$ & $-0.37(-0.79,0.04)$ & $71 \%$ \\
\hline \multirow[t]{2}{*}{ Test for subgroup differences } & & 0.05 \\
\hline & RR $(95 \%$ CI $)$ random effects & \\
\hline \multicolumn{3}{|l|}{ Trials with dichotomous outcome measures } \\
\hline \multicolumn{3}{|l|}{ Main analysis dichotomous outcome measures } \\
\hline - Acupuncture trials $(\mathrm{n}=5)$ & $0.86(0.67,1.11)$ & $68 \%$ \\
\hline - Other trials $(n=6)$ & $0.90(0.89,1.00)$ & $0 \%$ \\
\hline Test for subgroup differences & & 0,001 \\
\hline Acupuncture trials without Scharf, $2006(n=4)$ & $0.98(0.81,1.19)$ & $5 \%$ \\
\hline
\end{tabular}




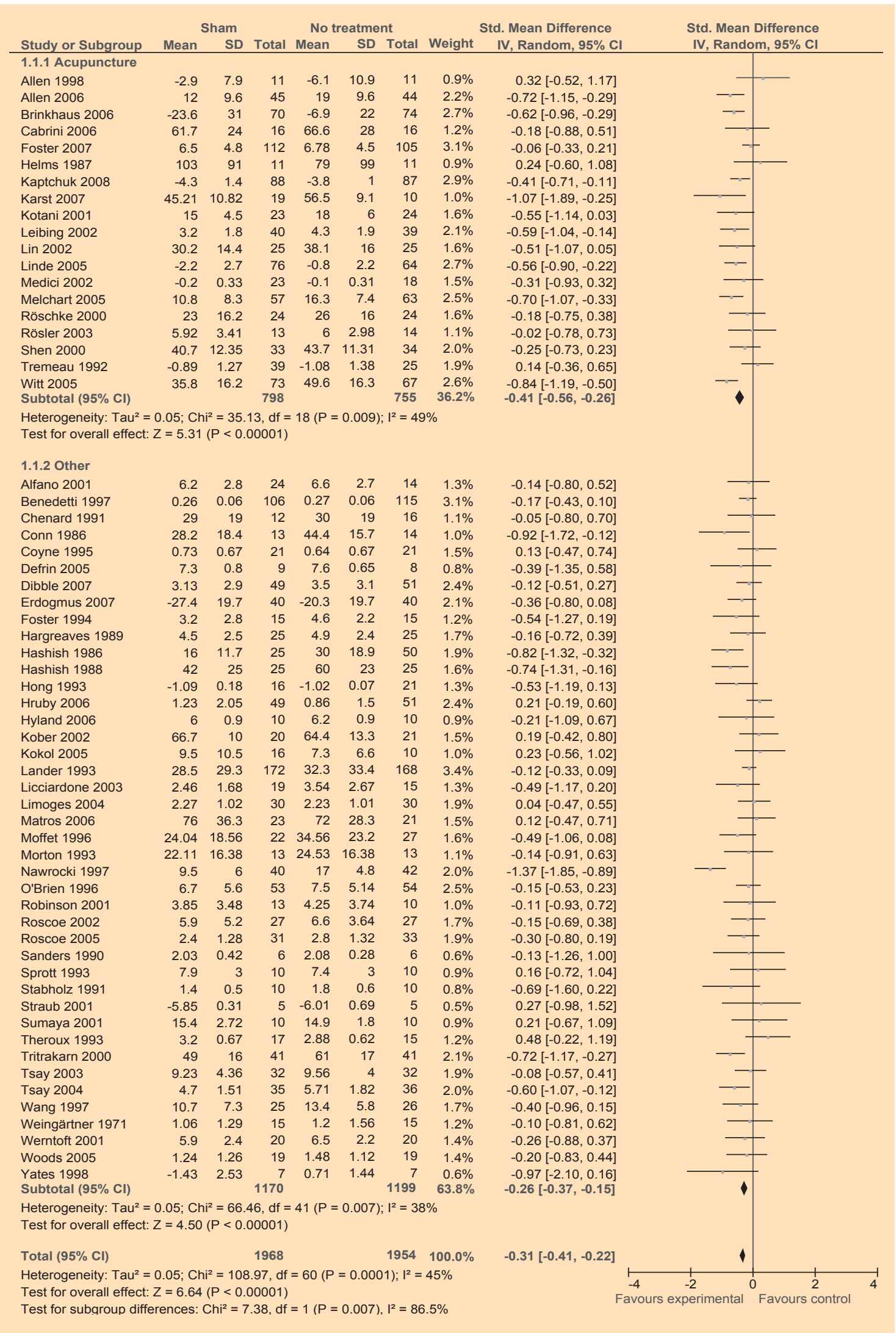

manipulations, and 10 trials were on various other therapies. The pooled random-effects SMD between sham interventions and no-treatment groups was -0.41 (95\% CI $-0.56,-0.26)$ for trials using sham acupuncture and -0.26 (95\% CI $-0.37,-0.15)$ for other studies with 'physical placebos' (test for subgroup differences $\mathrm{Chi}^{2}=7.37, \mathrm{p}=0.007$; fig. 1). Heterogeneity was 
moderate for both subgroups of trials with $\mathrm{I}^{2}$ being $49 \%$ and $38 \%$, respectively. According to Hrobjartsson and Gøtzsche, a series of 4 recent large acupuncture trials from Germany had considerable impact on the overall estimate. When these 4 trials [i.e. 12, 21, 23, 28] contributing to the analysis of continuous outcomes were excluded, the pooled effect estimate was reduced to -0.30 (95\% CI $-0.46,-0.13)$ and no longer differed significantly from that for non-acupuncture studies.

When we analyzed separately the different categories of 'physical placebos' other than sham acupuncture, SMDs between subgroups differed significantly (test for subgroup differences $\mathrm{Chi}^{2}=12.90, \mathrm{p}=0.01$; see table 2). The pooled SMD over no-treatment controls for placebos for electrotherapy, ultrasound or a physiotherapeutic intervention was slightly larger $(-0.52)$ than for sham acupuncture $(\mathrm{p}=0.44)$. The pooled random-effects relative risk (of a negative outcome) of the 5 studies which reported a dichotomous outcome measure for the comparison between the sham and the no-treatment group was $0.86(95 \%$ CI $0.67,1.11)$ for acupuncture studies and $0.94(95 \%$ CI $0.89,1.00)$ for other studies, confirming a larger effect of sham acupuncture ( $p$ value for differences between subgroups based on fixed-effects analyses $=0.001$ ). When the recent large German trial [33] was excluded from this analysis, the difference was non-significant.

\section{Discussion}

In our re-analysis of data from the Cochrane review by Hrobjartsson and Gøtzsche on placebo interventions for all kinds of conditions [8] sham acupuncture interventions were, on average, associated with larger effects over no-treatment control groups than were other 'physical placebos.' However, if the group of other 'physical placebos' was further subdivided there were also significant differences between subgroups.

Our results have to be interpreted with great caution. They are based on a re-analysis of a subgroup analysis from Hrobjartsson and Gøtzsche [8] with an indirect comparison of acupuncture and other trials. The trials included form an extremely heterogeneous sample and factors other than the sham interventions might have differed between the groups of trials compared. For example, it seems likely that effects of sham interventions vary between different conditions. Comparisons of sham acupuncture or other physical placebos and no-treatment groups cannot be blinded and many studies have measured subjective patient-rated endpoints. Furthermore, the extent of co-interventions in both sham or placebo and no-treatment groups was highly variable. The results are also clearly affected by a series of 5 recent large German trials which all found relatively large effects of sham acupuncture over no-treatment groups [i.e. 12, 21, 23, 28, 33]. These German trials have comparably high quality but if they are excluded, differences between sham acupuncture and other physical placebo are no longer significant. Therefore, further trials are required to investigate whether our findings are robust.

Despite these limitations, we believe that our results are a relevant contribution to the discussion on sham interventions in acupuncture research. There is accumulating evidence that effects associated with different placebo interventions can vary considerably. Some of this evidence comes from the Cochrane review which found that not only the type of placebo is an effect modifier, but also the information given to patients (trials not fully disclosing placebo use reported larger effects) or the purpose of the trial (trials explicitly investigating placebo effects reported larger effects). There is also some evidence from trials which directly compared different types of placebo $[3,5]$. Several systematic reviews indicate that factors like the dosage, the way of application or the number of physician contacts have an influence on response rates in placebo groups [34-36]. Findings from basic research strongly suggest that the specific context of an intervention has a major impact on the response to a (true or sham) intervention [37]. In the case of sham acupuncture direct physiological interventions associated with at least some sham interventions also might play an important role. In the light of this evidence it seems at least plausible that sham acupuncture interventions may often but - as it seems from the data - not always be associated with considerable effects. On average, these effects might be larger than those associated with pharmacological and other physical placebos.

\section{Acknowledgment}

We wish to thank Asbjørn Hrobjartsson for commenting on drafts of the manuscript.

\section{Disclosure Statement}

Funding for this project was neither applied for nor received. Part of this work has been performed for the MD thesis of Karin Niemann at the Technische Universität München. None of the authors has any conflict of interest to declare in relation to this article. 


\section{References}

1 Grünbaum A: The placebo concept in medicine and psychiatry. Psycholog Med 1986;16:19-38.

2 Hyland ME: A tale of two therapies: psychotherapy and complementary and alternative medicine (CAM) and the human effect. Clin Med 2005; 5:361-367.

3 Kaptchuk TJ, Goldman P, Stone DA, Stason WB: Do medical devices have enhanced placebo effects? J Clin Epidemiol 2000;53:786-792.

4 Birch S: A review and analysis of placebo treatments, placebo effects, and placebo controls in trials of medical procedures when sham is not inert. J Altern Complement Med 2006;12:303-310.

5 Kaptchuk TJ, Stason WB, Davis RB, Legedza ATR, Schnyer RN, Kerr CE, Stone DA, Huyn Nam B, Kirsch I, Goldman RH: Sham device v inert pill: randomised controlled trial of two placebo treatments. BMJ 2006;332:391-397.

6 Hrobjartsson A, Gotzsche PC: Placebo interventions for all clinical conditions. Cochrane Database Syst Rev 2004;CD003974.

7 Hrobjartsson A, Gotzsche PC: Is the placebo powerless? Update of a systematic review with 52 new randomized trials comparing placebo with no treatment. J Intern Med 2004;256:91-100.

8 Hrobjartsson A, Gotzsche PC: Placebo interventions for all clinical conditions. Cochrane Database Syst Rev 2010;CD003974.

9 Deeks J, Higgins J: Standard statistical algorithms in Cochrane review. Version 5. Statistical Methods Group of the Cochrane Collaboration. 2005. Available from www.cc-ims.net/revman/documentation/ Statistical-methods-in-RevMan-5.pdf.

10 Allen JJ, Schnyer RN, Chambers AS, Hitt SK, Moreno FA, Manber R: Acupuncture for depression: a randomized controlled trial. J Clin Psychiatry 2006;67:1665-1673.

11 Allen JJB, Schnyer RN, Hitt SK: The efficacy of acupuncture in the treatment of major depression in women. Psychol Sci 1998;9:397-401.

12 Brinkhaus B, Witt CM, Jena S, Linde K, Streng A, Wagenpfeil S, Irnich D, Walther HU, Melchart D, Willich SN: Acupuncture in patients with chronic low back pain: a randomized controlled trial. Arch Intern Med 2006;166:450-457.

13 Cabrini L, Gioia L, Gemma M, Melloni G, Carretta A, Ciriaco P, Puglisi A: Acupuncture for diagnostic fiberoptic bronchoscopy: a prospective, randomized, placebo-controlled study. Am J Chin Med 2006;34:409-415.

14 Foster NE, Thomas E, Barlas P, Hill JC, Young J, Mason E, Hay EM: Acupuncture as an adjunct to exercise based physiotherapy for osteoarthritis of the knee: randomised controlled trial. BMJ 2007;335:436
Helms JM: Acupuncture for the management of primary dysmenorrhea. Obstet Gynecol 1987;69: $51-56$

16 Kaptchuk TJ, Kelley JM, Conboy LA, Davis RB, Kerr CE, Jacobson EE, Kirsch I, Schyner RN, Nam BH, Nguyen LT, Park M, Rivers AL, McManus C, Kokkotou E, Drossman DA, Goldman P, Lembo AJ: Components of placebo effect: randomised controlled trial in patients with irritable bowel syndrome. BMJ 2008;336:999-1003.

17 Karst M, Winterhalter M, Munte S, Francki B, Hondronikos A, Eckardt A, Hoy L, Buhck H, Bernateck M, Fink M: Auricular acupuncture for dental anxiety: a randomized controlled trial. Anesth Analg 2007;104:295-300.

18 Kotani N, Hashimoto H, Sato Y, Sessler D, Yoshioka H, Kitayama M, Yasuda T, Matsuki A: Preoperative intradermal acupunture reduces postoperative pain, nausea and vomiting, analgesic requirement, and sympathoadrenal responses. Anesthesiology 2001;95:349-356.

19 Leibing E, Leonhardt U, Köster G, Gorlitz A, Rosenfeldt J-A, Hilgers R, Ramadori G: Acupuncture of chronic low-back pain - a randomized, blinded, placebo-controlled trial with 9-month follow-up. Pain 2002;96:189-196.

20 Lin JG, Lo MW, Wen YR, Hsieh CL, Tsai SK, Sun WZ: The effect of high and low frequency electroacupuncture in pain after lower abdominal surgery. Pain 2002;99:509-514.

21 Linde K, Streng A, Jurgens S, Hoppe A, Brinkhaus B, Witt C, Wagenpfeil S, Pfaffenrath V, Hammes MG, Weidenhammer W, Willich SN, Melchart D: Acupuncture for patients with migraine: a randomized controlled trial. JAMA 2005;293:2118-2125.

22 Medici TC, Grebski E, Wu J, Hinz G, Wüthrich B: Acupuncture and bronchial asthma: A long-term randomized study of the effects of real versus sham acupuncture compared to controls in patients with bronchial asthma. J Altern Complement Med 2002; 8:737-750.

23 Melchart D, Streng A, Hoppe A, Brinkhaus B, Witt C, Wagenpfeil S, Pfaffenrath V, Hammes M, Hummelsberger J, Irnich D, Weidenhammer W, Willich SN, Linde K: Acupuncture in patients with tension-type headache: randomised controlled trial. BMJ 2005;331:376-382.

24 Röschke J, Wolf C, Muller MJ, Wagner P, Mann K, Grozinger M, Bech S: The benefit from whole body acupuncture in major depression. J Affect Disord 2000;57:73-81.
Rösler A, Otto B, Schreiber-Dietrich D, Steinmetz H, Kessler KR: Single-needle acupuncture alleviates gag reflex during transesophageal echocardiography: a blinded, randomized, controlled pilot trial. J Altern Complement Med 2003;9:847-849.

26 Shen J, Wenger N, Glaspy J, Hays RD, Albert PS, Choi C, Shekelle PG: Electroacupuncture for control of myeloablative chemotherapy-induced emesis. A randomized controlled trial. JAMA 2000; 284:2755-2761.

27 Tremeau ML, Fontanie-Ravier P, Teurnier F, Demouzon J: [Protocol of cervical maturation by acupuncture]. J Gynecol Obstet Biol Reprod (Paris) 1992;21:375-380.

28 Witt C, Brinkhaus B, Jena S, Linde K, Streng A, Wagenpfeil S, Hummelsberger J, Walther HU, Melchart D, Willich SN: Acupuncture in patients with osteoarthritis of the knee: a randomised trial. Lancet 2005;366:136-143.

29 Aune A, Alraek T, LiHua H, Baerheim A: Acupuncture in the prophylaxisof recurrent lower urinary tract infection in adult women. Scand J Prim Health Care 1998;16:37-39.

30 Dundee JW, Chestnutt WN, Ghaly RG, Lynas AGA: Traditional Chinese acupuncture: a potentially useful emetic? BMJ 1986;293:583-584.

31 Fanti L, Gemma M, Passaretti S, Guslandi M, Testoni PA, Casati A, Torri G: Electroacupuncture analgesia for colonoscopy. A prospective, randomized, placebo-controlled study. Am J Gastroenterol 2003;98:312-316.

32 Molsberger AF, Mau J, Pawelec DB, Winkler J: Does acupuncture improve the orthopedic management of chronic low back pain - a randomized, blinded, controlled trial with 3 months follow up. Pain 2002;99:579-587.

33 Scharf HP, Mansmann U, Streitberger K, Witte S, Krämer J, Maier C, Trampisch HJ, Victor N: Acupuncture and knee osteoarthritis. A three-armed randomized trial. Ann Intern Med 2006;145:12-20.

34 de Craen AJ, Tijssen JG, de GJ, Kleijnen J: Placebo effect in the acute treatment of migraine: subcutaneous placebos are better than oral placebos. J Neurol 2000;247:183-188.

35 de Craen AJM, Moerman DE, Heisterkamp SH, Tytgat GNJ, Tijssen JGP: Placebo effect in the treatment of duodenal ulcer. Br J Clin Pharmacol 1999;48:853-860.

36 Posternak MA, Zimmerman M: Therapeutic effect of follow-up assessments on antidepressant and placebo response rates in antidepressant efficacy trials: meta-analysis. Br J Psychiatry 2007;190:287-292.

37 Benedetti F: Placebo effects. Understanding the mechanisms in health and disease. Oxford, Oxford University Press, 2009. 